\title{
Profiles of Compounds in Stover of Rice, Cymbopogon, Desmodium, Mucuna and Maize
}

\author{
M. G. Kaiira ${ }^{1}$, G. N. Chemining'wa ${ }^{2}$, F. Ayuke ${ }^{3} \&$ Y. Baguma ${ }^{4}$ \\ ${ }^{1}$ Buginyanya Zonal Agricultural Research and Development Institute, Mbale, Uganda \\ ${ }^{2}$ Department of Plant Science and Crop Protection, University of Nairobi, Nairobi, Kenya \\ ${ }^{3}$ Department of Land Resource Management and Agricultural Technology, University of Nairobi, Nairobi, \\ Kenya \\ ${ }^{4}$ National Crops Resources Research Institute (NaCRRI), Namulonge, Uganda \\ Correspondence: M. G. Kaiira, Buginyanya Zonal Agricultural Research and Development Institute, Mbale, \\ Uganda. E-mail: moseskaiira@gmail.com
}

Received: August 8, 2019

doi:10.5539/jas.v13n9p183

\author{
Accepted: October 1, 2019 \\ Online Published: August 15, 2021 \\ URL: https://doi.org/10.5539/jas.v13n9p183
}

\begin{abstract}
Crop residues and mulches release phytotoxic substances into the soil that affect plant growth. An experiment was conducted at the Uganda National Crop Resources Research Institute, Namulonge during 2016, to identify compounds in the stover of potted Cymbopogon nardus, Desmodium uncinatum, Oryza sativa, (NERICA 1), Mucuna pruriens and Zea mays (LONGE 6H) at fourty five days after germination. This marked near the average stationary phase for test crops' growth when secondary metabolites are maximum. Organic compounds in the stover were extracted using solid phase micro-extraction. Samples were subjected to analysis using a 7890A Gas Chromatography system. Data files were transferred into a distinct folder and data was uploaded onto XCMS online platform for pair wise comparison and other related statistical analysis in the National institute of Science and Technology library. Ten terpenoids and one ester were identified in cymbopogon stover. Desmodium stover released six terpenoids and three phenols. Rice stover produced six terpenoids, three phenolic compounds and one ester. Mucuna stover released two terpenoids and four phenols. The maize stover produced five terpenoids and four phenolic compounds. Profiled compounds from cymbopogon, desmodium, rice, mucuna and maize could be responsible for the reported negative allelopathic effects such as auto-toxicity and suppression of companion crops expressed in agricultural ecosystems. Allelopathic activity of the profiled compounds should be confirmed through bioassays extracts and residues studies. The development and incorporation of the profiled metabolites into agricultural management system may lead to the production of bio-herbicides that reduce environmental degradation and increase crop productivity.
\end{abstract}

Keywords: allelopathic, cymbopogon, desmodium, herbicides, organic, phenolic, rice, terpenoids

\section{Introduction}

Crop residues left in the soil release phytotoxic substances that are sometimes harmful to plant growth. The substances are produced by bacteria, fungi or plants as secondary metabolites that are organic in nature and not directly involved in the normal growth, development or reproduction of the organism. The major classes of the metabolites are phenolics, terpenoids, alkaloids and sulphur-containing compounds. Secondary metabolites are produced by plants in the secondary growth phase when the growth medium is depleted of nutrients. In eastern Uganda, upland rice ecosystems are basically mixed cropping or in companion with some plants that improve soil nutrient status, provide livestock feed or raw materials to farmers. The stovers from these crops are also often being used as mulching materials. However, the metabolites in the crop stover are not well known and could be allelopathic in nature, releasing phytotoxins into cultivated agricultural ecosystems.

Secondary metabolites have been reported in stover of different cultivars of rice, cymbopogon, desmodium, mucuna and maize. NERICA (New Rice for Africa) varieties (Oryza sativa $\times$ O. glaberrima) are a series of upland rice variety developed by the African Rice Center (AfricaRice, then WARDA) in the late 1990s (Jones et al., 1997). NERICA varieties are high yielding, early maturing and stress tolerant upland rice varieties. Kong et al. (2004) isolated two compounds; flavone (5,7,4'-trihydroxy-3',5'-dimethoxyflavone) and a cyclohexenone 
(3-isopropyl-5-acetoxycyclohexene-2-one-1) from leaves of allelopathic rice accession PI 312777. Kato-Noguchi et al. (2008) recorded momilactone $\mathrm{A}$ in the shoots and roots of all rice cultivars and concentrations differed among the cultivars. Presence of citral, geraniol, citronellol, citronellal, linalool, elemol, 1,8 -cineole, limonene, geraniol, $\beta$-caryophyllene, methyl heptenone, geranyl acetate and geranyl formate in the essential oils of different species of cymbopogon was made by Khanuja et al. (2005). Li et al. (2005) observed 12 components from volatiles of $C$. citratus shoots. The main component was citral (53.98\%), followed by z-citral (34.40\%) and the other components constituted less than $4 \%$. There were 2 monoterpenes and 9 sesquiterpenes in the volatiles from shoots.

There is little literature on secondary metabolites in desmodium, mucuna and maize stover. The available literature is hereby reviewed. Tsanuo et al. (2003) identified four isoflavanones in the root exudates of Desmodium uncinatum, namely 4",5"-dihydro-5,2',4'-trihydroxy-5"-isopropenylfurano-(2",3"; 7,6)isoflavanone(2), 5,7,4'trihydroxyisoflavone, 5,7,2',4'-tetrahydroxy-6-(3-methylbut-2-enyl) isoflavanones (1), and 4",5'-dihydro-2'methoxy-5,4'-dihydroxy-5"-isopropenylfurano-(2",3";7,6)-isoflavanone (3). Hooper et al. (2015) observed the major compound in the exudates of $D$. uncinatum as $C$-glycosylflavonoid. Vadivel and Pugalenthi (2008) reported the main (5\%) phenolic compound of Mucuna seeds as L-DOPA. Soares et al. (2014) similarly reported L DOPA to be exudated from the roots of mucuna. Kato-Noguchi (2010) identified 5-chloro-6-methoxy-2-benzoxazolinone (Cl-MBOA), 6-methoxy-2-benzoxazolinone (MBOA) and 2,4-dihydroxy-1,4-benzoxazin-3-one (DIBOA) as the three allelochemicals from the mesocotyls and coleoptiles of 5-day-old maize seedlings. The compounds p-coumaric and ferulic acids were identified in extracts of the dry stem, root, cob, husk, leaf and grain of maize by Gabriela et al. (2017).

Allelochemicals have been reported to affect seedling germination, crop growth, establishment and productivity. Chou and Lin (1976) reported that crop productivity of the second rice crop under paddy fields reduced when planted in the decomposing residues from the first rice crop. They also observed inhibited growth of mung bean, lettuce and rice due to aqueous extracts of decomposing residues in the soil. Aqueous extracts of rice residues were also found to suppress the growth of Lactuca sativa, Echnochloa crus-galli and Phalaris minor by Khan et al. (2001), and Jung et al. (2004). Ko et al. (2005) reported that husk extracts from Ilpum rice showed allelopathic effects on barnyard grass and it was observed that rice husks $\left(18 \mathrm{~L} \mathrm{ha}^{-1}\right)$ suppressed the weed density and dry weight up to 46 and $49 \%$ respectively by Cheema et al. (2010). Kaiira et al. (2019), similarly, reported that application of maize/rice/mucuna/cymbopogon mixed mulches significantly reduced the weed density by 51 and $60 \%$ at 42 and 90 days after emergence of rice (DAE) respectively. The researchers also recorded reductions in biomass per square metre of 17 and $33 \%$ of the control. The reductions in weed growth were attributed to inhibitory secondary metabolites in rice, cymbopogon, mucuna and maize stover on processes that influence weed growth.

Cymbopogon genus (Poaceae) is important for the essential oils and it is reported to possess antibacterial, antifungal, antiyeast, insecticidal and insect repellent properties. The essential oils in Cymbopogon species are biosynthesized in the rapidly growing leaves and stored in specific oil cells in the parenchymal tissues (Lewiinson et al., 1998; Luthra et al., 1999). The essential oil of $C$. citratus exhibited allelopathic activity and affected seed germination and seedling growth of corn and barnyard grass. Poonpaiboonpipat et al. (2013) reported that $C$. citratus essential oil damages the membrane system of barnyard grass (Echinochloa crus-galli L.), causing lipid peroxidation and electrolyte leakage. Barnyard grass, Italian ryegrass and jungle rice were reported as the most sensitive to the leaf, stalk and root extracts of $C$. nardus, respectively, by Suwitchayanon and Kato-Noguchi (2014). Krenchinsk et al. (2017) reported that the aqueous extract from C. citratus by maceration decreased germination and germination rates of Bidens pilosa and Bidens subalternans more than the aqueous extract by infusion for both species. The effects were concentration dependant. Yoshiharu (2003) reported that incorporation of fresh leaves of Mucuna pruriens into the soil $(1.0 \%) \mathrm{w} / \mathrm{w}$ in dry weight equivalent reduced succeeding emergence of Phaseolus vulgaris up to $60 \%$ and plant biomass up to $30 \%$ of the control. Travlos et al. (2018) similarly reported that velvet bean's residues reduced height, leaf number and biomass of rigid ryegrass up to 26,51 and $62 \%$, respectively. L-DOPA inhibited the growth of some companion plants, and that it probably contributed to its allelopathy. The study aimed at identifying the organic compounds in the stover of upland rice (NERICA 1), Cymbopogon nardus, Desmodium uncinatum, Mucuna pruriens and Zea mays (LONGE $6 \mathrm{H}$ ) that could be causing allelopathic properties in the crops. It was conducted by potting the test plants and samples were harvested for the extraction and analysis of potential organic compounds in the stover. Gas Chromatography and Mass spectrometry instrumental analysis were conducted and the National Institute of Science and Technology (NIST) library was utilised to identify the compounds. 


\section{Materials and Methods}

\subsection{Profiling of the Bioactive Compounds}

\subsubsection{Preparation of Plant Samples for Compound Analysis}

A screen house study was conducted at the Uganda National Crops Resources Research Institute, Namulonge in Uganda. Five 4-day old pre-germinated seeds each for rice, desmodium, mucuna and maize and five suckers of cymbopogon were potted separately and about $250 \mathrm{ml}$ of tap water was applied to each pot every two days for 40 days after seedling emergence (DAE). One plant of each species was uprooted (40 DAE), as representative samples, when the plants were near the stationary growth phase associated with maximum secondary metabolites. The samples were oven-dried at $80{ }^{\circ} \mathrm{C}$ for 12 hours to constant weight for compound analysis.

\subsubsection{Extraction and Analysis of Potential Organic Compounds From Plants Stover}

Organic compounds in stover were extracted using solid phase micro-extraction (SPME) and by solvent extraction. Prior to the extraction, the SPME fibre was preconditioned for one hour at $250{ }^{\circ} \mathrm{C}$ under a stream of helium inside the gas chromatograph (GC) injection port liner. The SPME fibre used was gauge $24,1 \mathrm{~cm}$ long, coated with divinyl benzene/polydimethylsiloxane and with $65 \mu \mathrm{M}$ film thickness. In a single manual injection, one gram of each plant sample was accurately weighed into a $10 \mathrm{ml}$ air tight glass vial. The sample and blank extractions were placed into a thermostat heated block at $60{ }^{\circ} \mathrm{C}$ for 1 hour with the fibre exposed to the headspace for the entire duration. The fibre was retracted and introduced into the injection port of the GC in splitless mode. One gram sample was accurately weighed into a $50 \mathrm{ml}$ extraction tube and extracted with $10 \mathrm{ml}$ of hexane by shaking at 250 revolutions per minute (rpm) in an orbital shaker for one hour. Two millilitre extract was aliquoted into an Eppendorf tube and centrifuged at $5000 \mathrm{rpm}$ for 10 minutes and $1 \mathrm{ml}$ extract was aliquoted into a $\mathrm{GC}$ vial for injection. One hundred milligrams of freeze dried samples were accurately weighed into $2 \mathrm{ml}$ Eppendorf and $1800 \mu \mathrm{L}$ of hexane was added with two mini steel balls placed inside the Eppendorf. The samples were vigorously ground in a genogrinder for 10 minutes. The extract was centrifuged at $5000 \mathrm{rpm}$ for 5 minutes and $200 \mu \mathrm{L}$ of extract was diluted with $800 \mu \mathrm{L}$ of hexane in a $\mathrm{GC}$ vial for injection.

\subsubsection{Gas Chromatography and Mass Spectrometry Instrumental Analysis Conditions}

Samples were subjected to analysis using a 7890A (Gas Chromatography) GC system (Agilent Technologies, USA) coupled to a 240 ion trap mass spectrometer (MS) detector (Agilent Technologies) using the Agilent 7693A automatic liquid sampler for solvent extracted samples. A VF5-MS (5\% phenyl methylpolysiloxane), 30 $\mathrm{m} \times 0.25 \mathrm{~mm}$ id, $0.25 \mu \mathrm{m}$ film capillary column was used with the injector port set at $280^{\circ} \mathrm{C}$. Helium was used as carrier gas at a flow rate of $1 \mathrm{ml} / \mathrm{min}$. The oven temperature was programmed to rise from $50{ }^{\circ} \mathrm{C}$ to $180{ }^{\circ} \mathrm{C}$ at $4{ }^{\circ} \mathrm{C} / \mathrm{min}$ followed by an increase to $250{ }^{\circ} \mathrm{C}$ at $3{ }^{\circ} \mathrm{C} / \mathrm{min}$. The ion trap mass spectrometer parameters were as follows: scan range $50-540(\mathrm{~m} / \mathrm{z})$, ionization mode EI and transfer line temperature, manifold temperature and trap temperature of $250^{\circ} \mathrm{C}, 100^{\circ} \mathrm{C}$ and $150^{\circ} \mathrm{C}$, respectively. Chromatograms and spectra representing individual samples were analyzed using the automated mass spectral deconvolution and identification system software (AMDIS, US). The identification of the individual compounds was performed by comparing each of the mass spectra with the database of NIST 11 (Gaithersburg, MD, USA) and Wiley 7N (John Wiley, NY, USA) and also by comparing the calculated Kovats linear retention indices using retention times of $n$-alkane series against the values obtained in the NIST web book for the same capillary column stationery phase.

\subsubsection{Chemometric Analysis of GC-MS Raw Data Using XC-MS Online Platform}

Data files in the common data formats corresponding to chromatograms from the various solvent extracted soil and SPME extracted volatiles in soil samples were obtained and transferred into a distinct folder. Data was uploaded onto XCMS online platform for pair-wise comparison and other related statistical analysis. The analysis was performed using the default parameters under the $\mathrm{GC} /$ single quad (centwave) method as it matched the instrument operating conditions. The results obtained included: retention time corrected, total ion chromatograms, principal component analysis (PCA) plots and an annotated report. The generated report was used to identify the log fold changes for various compounds earlier identified using AMDIS.

\section{Results}

\subsection{Bioactive Compounds Identified in the Stover of Rice, Cymbopogon, Desmodium, Mucuna and Maize}

\subsubsection{Bioactive Compounds Identified in Cymbopogon nardus Stover}

Data on capillary column stationary phase retention time, relative match factors and the compounds identified in the stover of C. nardus, D. uncinatum, O. sativa (NERICA 1), M. pruriens an Z. mays (LONGE 6H) are indicated in Tables 1-5. Ten terpenoids namely Citronellal, $\beta$-Citral, cis-Geraniol, trans-Carane, Eugenol, 
Geraniol acetate, $\beta$-Elemen, Caryophyllene, $\alpha$-Gurjunene and $\gamma$-Cadinene and one ester named Citronellyl butyrate were identified in Cymbopogon nardus stover (Table 1).

Table 1. Retention time, relative match factors and compounds in Cymbopogon nardus stover

\begin{tabular}{llll}
\hline Retention time (Min) & Relative match factor & Identified compound & Class of Compound \\
\hline 13.59 & 854 & Citronellal & Terpenoid \\
16.20 & 859 & Citronellyl butyrate & Ester \\
16.57 & 847 & $\beta$-Citral & Terpenoid \\
16.99 & 870 & cis-Geraniol & Terpenoid \\
20.24 & 874 & trans-Carane & Terpenoid \\
20.42 & 888 & Eugenol & Terpenoid \\
21.17 & 875 & Geraniol acetate & Terpenoid \\
21.60 & 862 & $\beta$-Elemen & Terpenoid \\
22.57 & 892 & Caryophyllene & Terpenoid \\
24.51 & 854 & $\alpha$-Gurjunene & Terpenoid \\
25.58 & 895 & $\gamma$-Cadinene & Terpenoid \\
\hline
\end{tabular}

\subsubsection{Bioactive Compounds Identified in Desmodium uncinatum Stover}

Nine organic compounds were profiled from the Desmodium uncinatum stover (Table 2). They included six terpenoids namely Butylated Hydroxytoluene, 1,2,3-Trimethyl-4-[(1E)-1-propenyl]naphthalene, 1,4-Eicosadiene, 1-Ethyl-2-(1-phenylethyl)benzene, 3,4-Diethyl-1,1'-biphenyl, 2,2'-Diethylbiphenyl and three phenols identified as 2,5-Di-tert-butylphenol, 3,7,11,15-Tetramethyl-2-hexadecen-1-ol and 3,7,11,15-Tetramethyl-2-hexadecen$1-\mathrm{ol}$.

Table 2. Retention time, relative match factors and compounds in Desmodium uncinatum stover

\begin{tabular}{llll}
\hline Retention time (Min) & Relative match factor & Identified compound & Class of compound \\
\hline 25.12 & 849 & Butylated Hydroxytoluene & Terpenoid \\
25.33 & 867 & 2,5-Di-tert-butylphenol & Phenol \\
29.57 & 845 & 3,4-Diethyl-1,1'-biphenyl & Terpenoid \\
30.15 & 863 & 1,2,3-Trimethyl-4-[(1E)-1-propenyl]naphthalene & Terpenoid \\
30.45 & 842 & 2,2'-Diethylbiphenyl & Terpenoid \\
31.02 & 785 & 1-Ethyl-2-(1-phenylethyl)benzene & Terpenoid \\
34.42 & 860 & 3,7,11,15-Tetramethyl-2-hexadecen-1-ol & Phenol \\
35.09 & 759 & (9Z)-9-Icosen-1-ol & Phenol \\
35.59 & 778 & 1,4-Eicosadiene & Terpenoid \\
\hline
\end{tabular}

\subsubsection{Bioactive Compounds Identified in Upland Rice (NERICA 1) Stover}

Rice (NERICA 1) stover produced 6 terpenoids namely 3,4-Diethyl-1,1'-biphenyl, 1,2,3-Trimethyl-4[(1E)-1-propenyl]naphthalene, 2,2'-Diethylbiphenyl, Butylated Hydroxytoluene, 1-Ethyl-2-(1-phenylethyl) benzene and 1,4-Eicosadiene (Table 3). Three phenols named 2,5-di-tert-butylphenol, 3,7,11,15Tetramethyl-2-hexadecen-1-ol and (9Z)-9-Icosen-1-ol and an ester called Hexadecanoic acid were also profiled in the rice stover. 
Table 3. Retention time, relative match factors and compounds in upland rice (NERICA 1) stover

\begin{tabular}{llll}
\hline Retention time (Min) & Relative match factor & Identified compound & Class of compound \\
\hline 25.13 & 849 & Butylated Hydroxytoluene & Terpenoid \\
25.32 & 845 & 2,5-Di-tert-butylphenol & Phenol \\
29.56 & 862 & 3,4-Diethyl-1,1'-biphenyl & Terpenoid \\
30.15 & 832 & 1,2,3-Trimethyl-4-[(1E)-1-propenyl]naphthalene & Terpenoid \\
30.45 & 865 & 2,2'-Diethylbiphenyl & Terpenoid \\
31.01 & 792 & 1-Ethyl-2-(1-phenylethyl)benzene & Terpenoid \\
34.40 & 874 & 3,7,11,15-Tetramethyl-2-hexadecen-1-ol & Phenol \\
35.07 & 803 & (9Z)-9-Icosen-1-ol & Phenol \\
35.60 & 782 & 1,4-Eicosadiene & Terpenoid \\
36.91 & 845 & Hexadecanoic acid & Ester \\
\hline
\end{tabular}

\subsubsection{Bioactive Compounds Identified in Upland Rice Mucuna pruriens Stover}

Compounds identified in the M. pruriens stover included 2 terpenoids namely Butylated Hydroxytoluene and 1,4-Eicosadiene and four phenols identified as 2,5-di-tert-butyl-Phenol, Hexa-hydro-farnesol, 3,7,11,15Tetramethyl-2-hexadecen-1-ol, (9Z)-9-Icosen-1-ol and (9Z)-9-Icosen-1-ol were also released from mucuna stover (Table 4).

Table 4. Retention time, relative match factors and compounds in Mucuna pruriens stover

\begin{tabular}{llll}
\hline Retention time (Min) & Relative match factor & Identified compound & Class of compound \\
\hline 25.13 & 856 & Butylated Hydroxytoluene & Terpenoid \\
25.32 & 841 & 2,5-di-tert-butyl- Phenol & Phenol \\
26.24 & 786 & Hexa-hydro-farnesol & Phenol \\
34.41 & 856 & $3,7,11,15-$ Tetramethyl-2-hexadecen-1-ol & Phenol \\
35.10 & 796 & (9Z)-9-Icosen-1-oll, & Phenol \\
36.60 & 814 & 4-Eicosadiene & Terpenoid \\
\hline
\end{tabular}

\subsubsection{Bioactive Compounds Identified in Upland Rice Zea mays (LONGE 6H) Stover}

Maize (LONGE 6H) stover released five terpenoids namely Ionene, 3,4-Diethyl-1,1'-biphenyl, Butylated Hydroxytoluene, 1,2,3-Trimethyl-4-[(1E)-1-propenyl]naphthalene, 1,4-Eicosadiene and four phenols identified as Falcarinol, 2,5-Di-tert-butylphenol, 3,7,11,15-Tetramethyl-2-hexadecen-1-ol and (9Z)-9-Icosen-1-ol (Table 5).

Table 5. Retention time, relative match factors and compounds in Zea mays (LONGE 6H) stover

\begin{tabular}{llll}
\hline Retention time (Min) & Relative match factor & Identified compound & Class of compound \\
\hline 20.51 & 876 & Falcarinol & Phenol \\
20.54 & 904 & Ionene & Terpenoid \\
25.13 & 903 & Butylated Hydroxytoluene & Terpenoid \\
25.32 & 896 & 2,5-Di-tert-butylphenol & Phenol \\
29.56 & 842 & 3,4-Diethyl-1,1'-biphenyl & Terpenoid \\
30.15 & 831 & 1,2,3-Trimethyl-4-[(1E)-1-propenyl]naphthalene & Terpenoid \\
34.41 & 856 & 3,7,11,15-Tetramethyl-2-hexadecen-1-ol & Phenol \\
35.09 & 879 & (9Z)-9-Icosen-1-ol & Phenol \\
38.58 & 812 & 1,4-Eicosadiene & Terpenoid \\
\hline
\end{tabular}

\section{Discussion}

In the study the whole plant stover (leaf, stem and root) was sampled to optimize on levels of the metabolites. Upland rice (NERICA 6H), Cymbopogon nardus, Desmodium uncinatum, Mucuna pruriens and Zea mays (LONGE $6 \mathrm{H})$ produced a wide range of metabolites in the stover that were dominated by Phenols and 
Terpenoids as the most important secondary metabolites. Ten terpenoids and one ester were identified in $C$. nardus stover. The results were supported by Khanuja et al. (2005) who revealed the presence of thirteen compounds namely citral, geraniol, citronellol, citronellal, linalool, elemol, 1,8-cineole, limonene, geraniol, $\beta$-caryophyllene, methyl heptenone, geranyl acetate and geranyl formate in the essential oils of different species of cymbopogon. Five of these compounds namely citral, geraniol, citronellal, geraniol and Caryophyllene were profiled in this study from the stover of $C$. nardus. This could be attributed to similarity in genetic characteristics for the test plants which were probably similar cultivars. Allelochemicals were reported to be more concentrated in the leaves, stems and roots of plants and to be released by volatilization, leaching, exudation and decomposition of plant materials (Rice, 1984; Aldrich, 1984). Khanuja et al. (2005) reported the essential oils of Cymbopogon citratus to exhibit allelopathic activity and affect seed germination and growth of corn and barnyard grass. Inhibitory effects of $C$. nardus on the shoot and root growth of cress, lettuce, rapeseed and Italian ryegrass were also observed by Prapaipit et al. (2013). Kaiira et al. (2019) observed no Striga hermonthica weed in rice mulched with $C$. nardus and attributed it to influences of compounds released by $C$. nardus. There is high potential to develop technologies for weed control from the secondary metabolites profiled from C. nardus under the current study.

Desmodium uncinatum stover produced six terpenoids and three phenols but no similar or related compounds are available in literature. Tsanuo et al. (2003) and Hooper (2015) have reported isoflavanones (Phenolic) as dominant in root exudates of Desmodium species. Khan et al. (2003) reported reduced parasitisation by Striga hermonthica and attributed it to allelochemicals from $D$. uncinatum intercrop. A putative allelopathic mechanism was observed when an aqueous solution from $D$. uncinatum was applied to $S$. hermonthica. Striga is a noxious obligate parasitic weed in cereals with chemotropic growth and has highest economic importance in Africa (Chang et al., 1986). Kim et al. (2002) reported 68\% yield losses with maize varieties due to striga and yield reductions of $52.6 \%$ were observed by Francis (2006) in sorghum. The compounds identified under this study could be responsible for some of the pest and weed control reported under D. uncinatum and could be further investigated for the potential development of control strategies for striga weeds in cereals.

Rice crop produced ten compounds in the stover which were identified as six terpenoids, three phenolic compounds and one ester. There are no similar compounds reported in literature on rice. This may be attributed to genetic variations and environmental influences. Allelopathy was observed to be quantitatively inherited by Kim and Shin (1998) who reported that allelopathy is influenced more by genetics than the environment. Four main effect quantitative trait loci located on three chromosomes were identified, which collectively explained $35 \%$ of the total phenotypic variation of the allelopathic activity in the population (Jensen et al., 2001). Several phenolic acids namely 2-hydroxyphenylacetic acid (3), 4-hydroxybenzoic acid (11), vanillic acid (16), p-coumaric acid (23) and ferulic acid (25) were found in aqueous extracts of decomposing rice residues (Chou and Lin 1976) and in soil from paddy fields which rice was grown (Chou and Chiou 1979). Five carboxylic acids and an aldehyde were identified from rice stover by Rimando and Duke (2003), while, Kong et al. (2004) isolated a flavone and one cyclohexenone from leaves of allelopathic rice accession PI 312777. Kato-Noguchi et al. (2008) reported that momilactone A was produced in the rice shoots and roots and concentrations differed among the cultivars. Several metabolites have been reported in root exudates of rice. Kong et al. (2006) reported that Allelopathic rice P1312777 and Huagan-1 released momilactone B, 3-isopropyl-5-acetoxycycloxexane-2-one-1 and 5,7,4'trihydroxy-3',5'-dimethoxyflavone into soil at phytotoxic levels. Kong et al. (2007) observed 5, 4-dihydroxy-3, 5-dimethoxy-7-O-b-glucopyranosylflavone, momilactone B, 3-isopropyl-5-acetoxy cyclohexene-2-one-1 and flavone O glycoside allelochemicals in rice roots exudates of PI 312777 cultivar. Kong et al. (2008) recorded reduced growth of Echinochloa crus-galli in paddy fields and attributed it to allelochemicals released by the roots of rice. Kaiira et al. (2019) reported that rice/cymbopogon/mucuna/maize mixed mulches inhibited weed density at 42 days after rice emergence (DAE) by $19-51 \%$ and at 90 DAE by $31-60 \%$. The weed biomass per square metre reduced at 42 and 90 DAE by $13-16 \%$ and $19-33 \%$, respectively, relative to the control. The effects were attributed to allelopathy. The metabolites identified in rice (NERICA 6H) under this study are a potential resource for development of weed control technologies.

Mucuna stover produced two terpenoids and four phenols but similar compounds had not been reported in literature. L-DOPA, a phenolic compound was reported as the dominant compound in mucuna vegetative parts (Vadivel \& Pugalethi, 2008; Travlos et al., 2018). Mucuna stover was observed to reduce root growth of lettuce seedlings by Tomita (2003). Mucuna leaves reduced the emergency and biomass of Phaseolus vulgaris (Yoshiramu, 2003). Nwaichi and Ayalogu (2010) observed reduced growth indices of companion crops with mucuna and attributed it to allelopathic influences of compounds from mucuna crop. Maize stover released five terpenoids and four phenolic compounds. But similar compounds could not be identified in literature. This may 
also be attributed to genetic variations. Secondary metabolites in the stover of Zea mays (LONGE 6H) and other varieties are not available in literature. Gabriela et al. (2015) identified p-coumaric and ferulic acids in extracts of the dry stem, root, cob, husk, leaf and grain of maize. Ayeni and Kayode (2014) reported inhibited germination, radicle and plumule length of Okra seeds using water extracts from maize root and tassel. Profiling the compounds in the stover of rice, cymbopogon, desmodium, maize and mucuna crops was a significant research achievement in this study. The secondary metabolites profiled could be responsible for the changes in growth of component crops in mixed cropping systems and for the associated crops and weeds, seedling mortalities and reduced productivity of the ecosystems. Further investigations on the allelopathic potential and activity of each compound should be conducted and confirmed through bioassays extracts and residues studies.

\section{Conclusion}

Compounds in plant stover of C. nardus, D. uncinatum, M. pruriens, O. sativa (NERICA 1) and Z. mays (LONGE 6H) were profiled. Terpenoids and phenolic compounds were the principal compounds identified and esters were profiled only in cymbopogon and rice stover. Some of the identified compounds may have allelopathic potential and could be responsible for a number of ecological and economic problems such as declines in crop yield due to low uptake of nutrients and reduced photosynthesis, plant regeneration failure and replant problems expressed by the test crops in natural and agricultural ecosystems. There is need to study the allelopathic potential of the specific compounds identified under specialized crop treatments to allow efficient generation of appropriate allelopathic cultivars through traditional breeding or biological based genetic alterations. Such cultivars could become important tools in the development of advanced integrated weed management.

\section{References}

Aldrich, J. D. (1984). Weed-crop ecology. Principles and practices (pp. 215-241). Breton Publishers.

Ayeni, M. J., \& Kayode, J. (2014). Laboratory studies on the effects of water extracts from Sorghum bicolor stem and Zea mays (Roots \& tassel) on the germination and seedling growth of Okra (Abelmoschus esculentus L.). Advances in Agriculture, 2014, Article ID 958503. https://doi.org/10.1155/2014/958503

Chang, M., Netzley, D. H., Butler, L. G., \& Lynn, D. G. (1986). Chemical regulation of distance: characterization of the first natural host germination stimulant for Striga asiatica. American Chemical Society, 108, 7858-7860. https://doi.org/10.1021/ja00284a074

Cheema, Z. A., Muhammad, Z., Ahmad, R., \& Murtaza, G. (2010). Application of allelopathic water extracts for suppressing the rice weeds. Crop Environment, 1, 1-5.

Chou, C. H., \& Chiou, S. J. (1979). Autointoxication mechanism of Oryza sativa. II. Effects of culture treatments on the chemical nature of paddy soil and on rice productivity. Journal of Chemical Ecology, 5, 839-859. https://doi.org/10.1007/BF00986568

Chou, C. H., \& Lin, H. J. (1976). Autointoxication mechanism of Oryza sativa, I. Phytotoxic effects of decomposing rice residues in the soil. Journal of Chemical Ecology, 2, 353-367. https://doi.org/10.1007/ BF00988282

Francis, A. S. (2006). Effect of Striga hermonthica on yield and yield components of sorghum in northern Guinea savanna of Nigeria. Journal of Plant Sciences, 1(1), 67-71. https://doi.org/10.3923/jps.2006.67.71

Gabriela, V., Leticia, X., Lopez, M., Laura, C. J., \& Heredia, B. (2017). Antioxidant capacity of lignin and phenolic compounds from corn stover. Waste and Biomass Valorization, 10, 95-102. https://doi.org/10.1007/ s12649-017-0028-5

Hooper, A. M., Caulfield, J. C., Hao, B., Pickett, J. A., Midega, C. A. O., \& Khan, Z. R. (2015). Isolation and identification of Desmodium root exudates from drought tolerant species used as intercrops against Striga hermonthica. Phytochemistry, 117, 380-387. https://doi.org/10.1016/j.phytochem.2015.06.026

Jensen, L, B., Courtois, B., Shen, L. S., Li, Z. K., Olofsdotter, M., \& Mauleon, R. P. (2001). Locating genes controlling allelopathic effects against barnyard grass in upland rice. Agronomy Journal, 93, 21-26. https://doi.org/10.2134/agronj2001.93121x

Jones, M. P., Dingkuhn, M., Aluko, K., \& Mande, S. (1997). Interspecific Oryza sativa L x O. glaberrima. Steud progenies in upland rice improvement. Euphytica, 92, 237-246. https://doi.org/10.1023/A:1002969932224 
Jung, W. S., Kim, K. H., Ahn, J. K., Hahn, S. J., \& Chung, I. M. (2004). Allelopathic potential of rice (Oryza sativa L.) residues against Echinocloa crusi-galli. Crop Protection, 23, 211-218. https://oi.org/10.1016/ j.cropro.2003.08.019

Kaiira, M. G., Chemining’wa, G. N., Ayuke, F., \& Baguma, Y. (2019). Crop mulches for increased weed control and rice productivity. International Journal of Plant \& Soil Science, 29(1), 1-14. https://doi.org/10.9734/ ijpss/2019/v29i130133

Kato-Noguchi, H. (2010). Potent allelopathic substances in maize. Allelopathy Journal, 18, 211-218.

Kato-Noguchi, H., Ota, K., \& Ino, T. (2008). Release of momilactone A and B from rice plants into the rhizosphere and its bioactivities. Allelopathy Journal, 22, 321-328.

Khan, A. H., Vaishya, R. D., Singh, H. H., \& Tripathi, J. S. (2001). Crop residues are allelopathic to Phalaris minor. Crop Protection Research, 22, 305-306.

Khan, Z. R., Hassanali, A., Pickett, J. A., Wadhams, I. J., \& Muyekho, F. (2003). Strategies for control of cereal stem borers and striga weed in maize-farming systems in Eastern Africa involving 'push-pull' and allelopathic tactics, respectively. African Crop Science Conference Proceedings, 6, 602-608.

Khanuja, S. P. S., Shasany, A. K., Pawar, A., Lal, R. K., Darokar, M. P., \& Naqvi, A. A. (2005). Essential oil constituents and RAPD markers to establish species relationship in Cymbopogon Spreng (Poaceae). Biochemical Systems and Ecology, 33, 171-186. https://doi.org/10.1016/j.bse.2004.06.011

Kim, K. U., \& Shin, D. H. (1998). Rice allelopathy research in Korea. In M. Olofsdotter (Ed.), Proceedings of the workshop on alelopathy in rice (pp. 31-44). Manilla, The Phillipines: International Rice Research Institute.

Kim, S. K., Adetimirin, V. O., The, C., \& Dossou, R. (2002). Yield losses in maize due to Striga hermonthica in west and central Africa. International Journal of Pest Management, 48(3), 211-217. https://doi.org/10.1080/ 009670870110117408

Ko, J., Eom, S. K., Kim, M. J., Yu, C. Y. \& Lee, Y. S. (2005). Allelopathy of rice husk on Barnyard grass. Journal of Agronomy, 4, 288-292. https://doi.org/10.3923/ja.2005.288.292

Kong, C. H., Wang, P., Zhao, H., Xu, X. H., \& Zhu, Y. D. (2008). Impact of allelochemicals exudated from allelopathic rice on soil microbial community. Soil Biology and Biochemistry, 40, 1862-1869. https://doi.org/10.1016/j.soilbio.2008.03.009

Kong, C. H., Zhao, H., Xu, X. H., Wang, P., \& Gu, Y. (2007). Activity and allelopathy of soil of flavone O-glycosides allelochemicals from rice. Journal of Agriculture and Food Chemistry, 55, 6007-6012. https://doi.org/10.1021/jf0703912

Kong, C., Li, H. B.., Xu, Hu, F., Xu, X. H., \& Wang, P. (2006). Allelochemicals released by rice residues and roots in soil. Plant and Soil, 288(1-2), 47-56. https://doi.org/10.1007/s11104-006-9033-3

Kong, C., Xu, X., Bin Zhou, B., Zhang, C., \& Zhang, M. (2004). Two compounds from allelopathic rice accession and their inhibitory activity on weeds and fungal pathogens. Phytochemistry, 65(8), 1123-1128. https://doi.org/10.1016/j.phytochem.2004.02.017

Krenchinski, F. H., Albrecht, L. P., Albrecht, A. J. P., Zonetti, P. C., Tessele, A., Barroso, A. A. M., \& Placido, F. H. (2017). Allelopathic potential of Cymbopogon citratus over beggarticks (Bidens spp.) germination. Australian Journal of Crop Science, 11(03), 277-283. https://doi.org/10.21475/ajcs.17.11.03

Lewinsohn, E., Dudai, N., Tadmor, Y., Katzir, I., Ravid, U., \& Putievsky, E. (1998). Histochemical localization of citral accumulation in lemongrass leaves (Cymbopogon citratus (DC) stapf. Poaceae). Annals of Botany, 81, 35-39. https://doi.org/10.1006/anbo.1997.0525

Li, H., Huang, J., Zhang, X., Chen, Y., Yang, J., \& Hei, L. (2005). Allelopathic effect of Cymbopogon citratus volatile and its chemical components. Ying Yong Sheng Tai Xue Bao, 16(4), 763.

Luthra, R., Luthra, P. M., \& Kumar, S. (1999). Redefined role of mevalonate-isoprenoid pathway in terpenoid biosynthesis in higher plants. Current Science, 76, 133-35.

Nwaichi, E. O., \& Ayalogu, E. O. (2010). Allelopathy as expressed by Mucuna pruriens and the possibility for weed management. International Journal of Plant Physiology and Biochemistry, 2(1), 1-5.

Poonpaiboonpipat, T., Pangnakorn, U., Suvunnamek, U., Teerarak, M., Charoenying, P., \& Laosinwattana, C. (2013). Phytotoxic effects of essential oil from Cymbopogon citratus and its physiological mechanisms on 
barnyard grass (Echinochloa crus-galli). Indian Crop Production, 41, 403-407. https://doi.org/10.1016/ j.indcrop.2012.04.057

Prapaipit, S., Piyatida, P., \& Kato-Noguchi, H. (2013). Allelopathic activity of Cymbopogon nardus (Poaceae). Journal of Plant Studies, 2(2), 1. https://doi.org/10.5539/jps.v2n2p1

Rice, E. L. (1984). Allelopathy (2nd ed.). Academic Press.

Rimando, A. M., \& Duke, S. O. (2003). Studies on rice allelochemicals. In C. W. Smith \& R. H. Dilday (Eds.), Rice: Origin, History, Technology and Production (pp. 221-244). John Wiley \& Sons, Inc., Hoboken, New Jersey.

Soares, A. R., Marchiosi, R., Signeira. S. R., Barbosa, L. R., Dantas, S. W., \& Farrarese, F. O. (2014). The role of L-DOPA in plants. Plant Signaling and Behavior, 9, e28275. https://doi.org/10.4161/psb.28275

Suwitchayanon, P., \& Kato-Noguchi, H. (2014). Allelopathic activity of leaves, stalks and roots of Cymbopogon nardus. Emir. Journal of Food and Agriculture, 26(5), 436-443. https://doi.org/10.9755/ejfa.v26i5.17226

Tomita, K., Fujii, Y., Yoshida, S., Hashimoto, H., \& Yamashita, M. (2003). Volatile allelopathy in velvet bean (Mucuna pruriens L.) and gravity. Biological Sciences in Space, 17(3), 212-3.

Travlos, I., Ioannis Roussis, I., Roditis, C., Semini, C., Rouvali, L., Stasinopoulou, P., ... Dimitrios, V. C. (2018). Allelopathic potential of velvet bean and Chia against rigid rye grass. Notulae Botanicae Horti Agrobotanici Cluj-Napoca, 46(1), 173-176. https://doi.org/10.15835/nbha46110941

Tsanuo, M. K., Hassanali, A., Hooper, A. M., Khan, Z, Kaberia, F., Pickett, J. A., \& Wadhams, L. J. (2003). Isoflavanones from the allelopathic aqueous root exudate of Desmodium uncinatum. Phytochemistry, 64(1), 265-73. https://doi.org/10.1016/S0031-9422(03)00324-8

Vadivel, V., \& Pugalenthi, M. (2008). Removal of anti-nutritional/toxic substances and improvement in the protein digestibility of velvet bean seeds during various processing methods. Journal of Food Science and Technology, 45, 242-246.

Yoshiharu, F. (2003). Allelopathy in natural and agricultural ecosystems and isolation of potent allelochemicals from velvet beans (Mucuna pruriens) and hairy vetch (Vicia villosa). Biological Sciences in Space, 17(1), 6-13. https://doi.org/10.2187/bss.17.6

\section{Copyrights}

Copyright for this article is retained by the author(s), with first publication rights granted to the journal.

This is an open-access article distributed under the terms and conditions of the Creative Commons Attribution license (http://creativecommons.org/licenses/by/4.0/). 